\title{
Research Paper: Effect of Rehabilitation Interventions on Sensation, Function, and Pain of the Patients With Carpal Tunnel Release
}

\author{
Roya Mahmoodi $^{1}$ (D), Maryam Farzad $^{1 *}$ (D), Amir Kachooei ${ }^{2}$ (D), Fereydoun Layeghi ${ }^{3}$, Erfan Shafiee ${ }^{1}$ (D) \\ 1. Departemant of Occupational Therapy, University of Social Welfare and Rehabilitation Sciences, Tehran, Iran \\ 2. Orthopedic Research Center, Mashhad University of Medical Sciences, Mashhad, Iran. \\ 3. Departemant of Clinical Sciences, University of Social Welfare and Rehabilitation Sciences, Tehran, Iran.
}

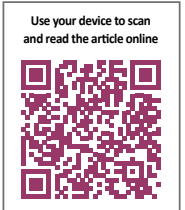

Citation: Mahmoodi R, Farzad M, Kachooei A, Layeghi F, Shafiee E. Effect of Rehabilitation Interventions on Sensation, Function, and Pain of the Patients With Carpal Tunnel Release. Iranian Rehabilitation Journal. 2019; 17(3):263-270. http:// dx.doi.org/10.32598/irj.17.3.263

http://dx.doi.org/10.32598/irj.17.3.263

Article info:

Received: 26 Jan 2019

Accepted: 05 May 2019

Available Online: 01 Sep 2019

Keywords:

Carpal tunnel syndrome, Carpal tunnel release, Rehabilitation

\section{ABSTRACT}

Objectives: Carpal Tunnel Syndrome (CTS) is now the most common type of nerve compression neuropathies constituting about (90\%) of the neuropathic disorders. To attain the optimal recovery following the operation, a rehabilitation intervention is urgent. This study aims at investigating the efficacy of short and long term rehabilitation interventions following Carpal Tunnel Release (CTR) on motor functions, sensory, and pain.

Methods: Thirty patients were randomly assigned to two groups after CTR. The intervention group received rehabilitation exercises within a week after the operation, and the control group received a progressive home exercise program. The patients were assessed in terms of pain, sensation, function (measured by Boston Questionnaire), pinch, and grip (measured by dynamometer) in three periods of time, before operation, 6 weeks, and 12 weeks after operation by Visual Analogue Scale (VAS), Semmes Weinstein Test of Monofilaments, Boston questionnaire test, and dynamometer.

Results: No significant differences in function were seen between the two groups $(\mathrm{P}=0.28)$ The average score of pain decreased. In spite of the increase in sensory score in the intervention group, no significant difference was found $(\mathrm{P}=0.19)$. A considerable difference was found in pain, grip, and pinch between the two groups during the first 6 weeks after the operation.

Discussion: The rehabilitation interventions, even in short term, affect the pain and power (pinch and grip). Also, they facilitate returning to work. In the long term, however, there were no considerable diversities. In other words, improvements gained in two groups are the same in the long-term.

\footnotetext{
* Corresponding Author:

Maryam Farzad, PhD.

Address: Departemant of Occupational Therapy, the University of Social Welfare and Rehabilitation Sciences, Tehran, Iran.

Tel: +98 (912) 3020429

E-mail: maryam_frzd@yahoo.com
} 


\section{Highlights}

- Rehabilitation interventions following carpal tunnel release do not affect function and sensation in the long term.

- Pain relief happens quicker after having rehabilitation interventions following carpal tunnel release.

- Rehabilitation interventions following carpal tunnel release can enhance power and diminish pain in the short term, and this facilitates return to work.

\section{Plain Language Summary}

Carpal tunnel syndrome is one of the most common injuries of the hand. Most of the cases undergo Carpal Tunnel Release (CTR), a simple procedure to decrease the pressure on the median nerve. The effectiveness of rehabilitation interventions following CTR has been a matter of debates over the past years. The results of this study demonstrate that people who receive rehabilitation after CTR may have pain relief sooner than those who do not receive rehabilitation, and they are likely to return to work sooner.

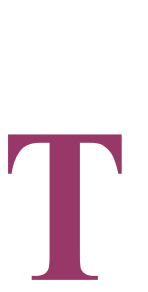

\section{Introcution}

he high incidence and problems in sensation and function have made Carpal Tunnel Syndrome (CTS) one of the most common points of debates and discussions [1]. CTS can be treated non-operatively with rehabilitation interventions and conservative management or in the mild and severe forms with the release of the carpal tunnel. Based on American Academy of Orthopedic Surgeons guideline reports, in mild or severe conditions, the surgical release of the carpal tunnel has a lot of benefits in 6 to 12 months in comparison with conservative treatments [2-5]. There is no sufficient evidence in the benefits of conservative treatments after Carpal Tunnel Release (CTR).

A little evidence was reported in Cochrane Review [2] in favor of rehabilitation interventions such as immobilization, dressing, exercise, cold and ice therapy, laser therapy, electrical treatments, scar desensitization, and arnica, most of which can facilitate recovery and pain management after the operation. These interventions promote recovery by improving mobility, the strength of the hand, as well as promoting early return to work [6, 7]. Rehabilitation interventions may also be efficient in relieving iatrogenic issues such as postoperative swelling, scar desensitization, management of pillar pain, and wound healing [8]. Even though so many studies could be found in favor of the efficiency of rehabilitation after CTR, the high-level evidence does not exist [2].
This study aimed at comparing the short-term (6 weeks) and intermediate-term (12 weeks) effects of multidisciplinary rehabilitation interventions on pain, sensation, and function of the patients after CTR. Our primary null hypothesis states that there is no difference between receiving and not receiving rehabilitation interventions after CTR.

\section{Methods}

This is a single-blind randomized controlled trial with a 12-week follow-up period. The patients were allocated to the intervention and control groups before their surgical intervention based on the inclusion criteria. The patients were excluded if they had thenar atrophy, or any accompanying orthopedic or neurological disorders that could mimic CTS or exultance of double crush syndrome. After CTR, patients were randomly assigned to one of the two groups. The intervention group received rehabilitation exercises depending on the patient's conditions within a week after the operation, and the control group received a progressive home exercise program.

\section{Study participants}

Thirty-five participants included before CTR, 5 of whom were excluded according to the exclusion criteria. Thirty patients after CTR (all women; Mean \pm SD age: $51 \pm 9$ y, range: $20-73 \mathrm{y}$; Mean \pm SD BMI: $25.39 \pm 4.25 \mathrm{~kg}$ / $\mathrm{m}^{2}$, range: $16.00-36.84 \mathrm{~kg} / \mathrm{m}^{2}$ ) were randomly assigned to the two groups. The mean duration of having this condition was 30 months (standard deviation: $36.8 \mathrm{~m}$; range: $1-120 \mathrm{~m}$ ); 28 patients were right-handed (Table 1). A total 
of $(60 \%)$ of the participants presented severe symptoms with the Mean \pm SD pain intensity of $7.5 \pm 1.5$. The duration of symptoms ranged from 4 months to 3 years.

\section{Assignment and blinding}

An assistant hand therapist, who was blind to the treatment, performed the randomization, using concealed envelopes after gathering patients' baseline data. Because of the nature of the intervention, it was difficult to blind the patients. An occupational therapist, who was blind to treatment allocation, performed the assessments.

\section{Study intervention}

The study patients had a CTR in their both hands. The intervention group received rehabilitation treatment, which started one week after the operation. The techniques included nerve gliding, splinting, massage, tendon gliding, and strengthening of the muscles innervated by median nerve based on the severity and duration of the symptom according to the multidisciplinary guideline $[9,10]$. The control group was instructed to have progressive home exercise based on their endurance and power (pinch and grip).

\section{Outcome measures}

Functional status, pain intensity, sensation, pinch, and power were evaluated at baseline (before operation) at 6 and 12 weeks after surgery. Because 6 weeks is enough for improvement in symptoms, the first evaluation time was set at six weeks after CTR. Moreover, treatment would be effective if any improvement occurs within the first 12 weeks $[11,12]$. Therefore, 12week follow-up may be sufficient to evaluate whether rehabilitation programs have added benefit to CTR.

\section{Boston carpal tunnel questionnaire}

The Boston Carpal Tunnel Questionnaire is a 19-item questionnaire assessing the severity of symptoms and functional status of the patients with CTS. It consists of two subscales; Symptom Severity Scale (SSS; 11 items) and Functional Status Scale (FSS; 8 items). It is scored with a 5-point scoring system; higher scores indicate more complication $[13,14]$. The minimal clinically important difference in the SSS and FSS scores are (0.8) and (0.5) points, respectively [15].

\section{Visual analog scale}

The participants were asked to point their average level of pain within the past week, using an 11-point scale, ranging from 0 (no pain) to 10 (maximum pain) [16].

A change of two points or a (30\%) decrease in pain intensity from baseline was considered a Minimal Clinical Important Difference (MCID) [17].

\section{Sensory evaluation}

We evaluated the sensory thresholds by the SemmesWeinstein Monofilament test kit (North Coast Medical, Inc., USA). The kit consists of 20 flexible nylon monofilaments of varying diameters and lengths to measure the level of skin touch sensation. The monofilaments have log numbers from (1.65) to (6.65), which begins with the light filaments (1.65-3.61) and progresses to heavy filaments of increasing diameter (3.84-6.65). Heavy filaments need increased pressure to be recognized by patients in touch. The tester put each monofilament three times to the surface of the skin with a perpendicular angle and then applies slight and steady pressure until the monofilament begins to bend, one correct response out of three trials considered as a normal threshold. The monofilament number of (2.83) was defined as the cut-off for normal sensation [18].

\section{Pinch and grip}

The measurement of power grip and tip pinch, key pinch, and tripod pinch were performed, using a hydraulic grip dynamometer and hydraulic gauge pinch dynamometer (Irvington, NY., USA) [19].

\section{Sample size determination}

The sample size was calculated to detect an effect size: (1.06) with an alpha level of (0.05) and the desired power of $(80 \%)$. The estimated desired sample size was at least 14 participants per group (28 participants in total). Thirty-five patients were included to compensate for potential drop out.

\section{Statistical analysis}

Statistical analysis was performed in SPSS V. 18 and conducted according to intention-to-treat analysis for patients in the group, to which they were allocated. When some data were missing, the Last Observation Carried Forward (LOCF) would be applied. 
Baseline demographic and dependent variables were compared between groups, using the Independent $t$ test for continuous data and $\mathrm{X}^{2}$ test of independence for categorical data.

The differences between groups and within groups calculated by mixed-model repeated measured effect sizes were obtained by dividing the mean score differences between groups by the pooled standard deviation.

\section{Results}

There were no statistical differences in the proportions age, pain level, function, severity, and sensation in the baseline $(\mathrm{P}>0.05)$ (Tables 2 and 3$)$. The mean difference of function and sensation between the two groups in two sets of measurements were not significant $(\mathrm{P}=0.28)(\mathrm{P}=0.19)$ (Table 3$)$. The pain was relieved in the intervention group $(\mathrm{P}=0.04)(\mathrm{CI}=-2.25-3.65)$. The differences were statically significant in terms of tip pinch, key pinch, and grip strength $(\mathrm{P}=0.05,0.04$, and 0.04 , respectively). Even though power and pinch increased in the intervention group in 6 weeks $(\mathrm{P}<0.05)$, they were not significant in 8 weeks (Table 4). Small effect size (1.08) was detected in the measurement of the primary outcome (function).

\section{Discussion}

Rehabilitation interventions are not a routinely prescribed method after CTR. Some surgeons believe in training home graded exercise for the patients after the operation without any supervised rehabilitation, whereas others recommend active supervised hand therapy and splinting. There is little research available on the clinical relevance of hand therapy after CTR. Some authors believe in using a splint to keep the wrist in a neutral position [20].

Table 1. Demographic characteristics of the study participants $(n=30)$

\begin{tabular}{cccc}
\hline Baseline Variables & \multicolumn{1}{c}{ The Intervention Group } & The Control Group \\
\hline Age, $y$, Mean \pm SD & Illiterate & $31.8 \pm 8.57$ & $49.27 \pm 10.23$ \\
Level of Education, No.(\%) & Educated & $12(80)$ & $3(20)$ \\
$\begin{array}{c}\text { Dominant hand, } \\
\text { No.(\%) }\end{array}$ & Right & $14(93.3)$ & $12(80)$ \\
$\begin{array}{c}\text { Left } \\
\text { Injured hand, }\end{array}$ & $1(6.7)$ & $14(93.3)$ \\
No.(\%) & Right & $9(60)$ & $1(6.7)$ \\
Left & $6(40)$ & $5(33.3)$ \\
Extent of Injury, & Mild & $6(40)$ & $10(66.7)$ \\
No.(\%) & Severe & $9(60)$ & $2(13.3)$ \\
\hline
\end{tabular}

Table 2. Mean $\pm S D$ of variables at baseline in both groups

\begin{tabular}{ccc}
\hline & & Mean \pm SD \\
Baseline Variables & Intervention Group & Control Group \\
\cline { 2 - 3 } & $51.80 \pm 8.57$ & $49.27 \pm 10.23$ \\
Age, $y$ & $7.53 \pm 1.45$ & $6.40 \pm 2.23$ \\
Pain & $39.67 \pm 8.20$ & $34.47 \pm 7.87$ \\
Symptoms & $25.07 \pm 6.41$ & $20.60 \pm 7.98$ \\
Function & $2.00 \pm 1.06$ & $2.33 \pm 0.90$ \\
\hline
\end{tabular}


Table 3. Mean $\pm S D$ of pain, sensation, and function in the study groups

\begin{tabular}{ccccccc}
\hline \multirow{2}{*}{ Pain, Sensation and Function } & \multicolumn{5}{c}{ Control \& Intervention } \\
\cline { 2 - 7 } & \multicolumn{2}{c}{ Pain } & \multicolumn{2}{c}{ Sensation } & Function \\
\hline Before operation & $2.23 \pm 6.40$ & $1.45 \pm 7.53$ & $0.90 \pm 2.33$ & $1.06 \pm 2.00$ & $7.98 \pm 20.60$ & $6.41 \pm 25.07$ \\
\hline Six weeks after operation & $2.41 \pm 4.40$ & $1.55 \pm 5.47$ & $0.70 \pm 1.73$ & $0.64 \pm 1.47$ & $6.40 \pm 17.27$ & $4.54 \pm 18.33$ \\
\hline Eight weeks after operation & $2.42 \pm 3.00$ & $1.73 \pm 4.00$ & $0.61 \pm 1.67$ & $0.48 \pm 1.33$ & $6.60 \pm 15.07$ & $3.90 \pm 15.67$ \\
\hline $\mathrm{P}^{*}$ & \multicolumn{2}{c}{0.047} & 0.19 & 0.28 \\
\hline
\end{tabular}

*P>0.05

Iranian Rehabilitation Wournal

Table 4. Mean $\pm S D$ of grip, key pinch and tip pinch values in the study groups

\begin{tabular}{|c|c|c|c|c|c|c|}
\hline \multirow{3}{*}{$\begin{array}{l}\text { Pinch and Power } \\
\text { Before operation }\end{array}$} & \multicolumn{6}{|c|}{ Control \& Intervention } \\
\hline & \multicolumn{2}{|c|}{ Grip } & \multicolumn{2}{|c|}{ Key Pinch } & \multicolumn{2}{|c|}{ Tip Pinch } \\
\hline & $7.79 \pm 25.96$ & $9.98 \pm 24.53$ & $7.42 \pm 29.66$ & $7.57 \pm 22.63$ & $7.65 \pm 23.5$ & $7.70 \pm 18.20$ \\
\hline Six weeks after operation & $6.37 \pm 19.93$ & $9.32 \pm 28.53$ & $5.99 \pm 22.20$ & $4.21 \pm 30.93$ & $6.57 \pm 18.3$ & $4.86 \pm 26.3$ \\
\hline Eight weeks after surgery & $6.16 \pm 22.36$ & $8.37 \pm 31.56$ & $5.52 \pm 24.06$ & $3.77 \pm 34.26$ & $7.29 \pm 20.43$ & $3.13 \pm 30.46$ \\
\hline $\mathrm{P}^{*}$ & \multicolumn{2}{|c|}{0.046} & \multicolumn{2}{|c|}{0.043} & \multicolumn{2}{|c|}{0.050} \\
\hline
\end{tabular}

$* \mathrm{P}>0.05$

Iranian Rehabilitation Journal

Based on a recent review on the effectiveness of postsurgical rehabilitation after CTR, only two RCTs found moderate evidence for the effectiveness in the short-term results in sensory and power recovery after CTS operation. In none of them, RCT-scheduled rehabilitation interventions were not used [21]. Based on this review, there is no RCT to compare the result of a multidisciplinary rehabilitation method after CTR. This multidisciplinary treatment guideline was suggested to provide patients with CTS with the most effective and efficient treatment available with European Hand Surgery Association [21]. Using a multidisciplinary approach in this study can be considered a novelty for the results.

In the present study, starting rehabilitation after CTR can enhance pinch and power in the short term. Some reports have investigated the effect of starting active rehabilitation on improving pinch and grip strength at 6- to 12-week follow-up [22].

Based on the result of this study, post-operative rehabilitation does not have any priority in favor of function and sensation in the long term. These results are consistent with previous studies that investigated the effect of rehabilitation in improving sensation [23]. Pain can be relieved sooner after rehabilitation interventions, and this difference can also be seen in 12 weeks after the operation. Effect of using splinting on pain also was positive in some studies [2].

Rehabilitation after CTR can enhance power and diminish pain in the short term, and this can facilitate returning to work and starting the activities of daily living in patients. Using postoperative interventions after CTR can be used for patients who want to return to their work as soon as possible. As there is no difference in pain reduction, improving power, and function in the long term, simple home exercises can be enough for patients to gain their functions. This can be a cost-benefit treatment after CTR.

\section{Conclusions}

Rehabilitation interventions, even in the short term, is useful in the improvement of pain and strength. Also, they facilitate returning to work. In the long term, no considerable difference is seen. 


\section{Ethical Considerations}

\section{Compliance with ethical guidelines}

The Institutional Review Board of our university approved this study (Code: IRCT2017041233390N1). and all of them signed written informed consent form before beginning the experiment. Informed consent was obtained from all patients for being included in the study.

\section{Funding}

The authors received no financial support for the research, authorship, and or publication of this article.

\section{Authors' contributions}

Conceptualization and methodology: Maryam Farzad, Fereydoun Layeghi, Amir Kachoei; Investigator: Roya Mahmoudi; Writing helps: Erfan Shafiee

\section{Conflict of interest}

The authors declared no conflict of interest.

\section{References}

[1] Piazzini, DB, Aprile I, Ferrara PE, Bertolini C, Tonali P, Maggi L, et al. A systematic review of conservative treatment of carpal tunnel syndrome. Clinical Rehabilitation. 2007; 21(4):299-314. [DOI:10.1177/0269215507077294] [PMID]

[2] Peters S, Page MJ, Coppieters MW, Ross M, Johnston V. Rehabilitation following carpal tunnel release. Cochrane Database of Systematic Reviews. 2013; (6):CD004158. [DOI:10.1002/14651858.CD004158.pub3] [PMID]

[3] Cooke ME, Duncan SF. History of carpal tunnel syndrome. Carpal tunnel syndrome and related median neuropathies. Cham, Switzerland: Springer; 2017. [DOI:10.1007/978-3319-57010-5_2] [PMCID]

[4] 4. Keith MW, Masear V, Chung CK, Amadio PC, Andary M, Graham B, et al. American academy of orthopaedic surgeons clinical practice guideline on the treatment of carpal tunnel syndrome. The Journal of Bone and Joint Surgery. 2010; 92:218-9. [DOI:10.2106/JBJS.I.00642]

[5] Keith MW, Masear V, Amadio PC, Andary M, Barth RW, Graham B, et al. Treatment of carpal tunnel syndrome. Journal of the American Academy of Orthopaedic Surgeons. 2009; 17(6):397-405. [DOI:10.5435/00124635-20090600000008] [PMID]

[6] Provinciali L, Giattini A, Splendiani G, Logullo F. Usefulness of hand rehabilitation after carpal tunnel surgery. Muscle \& Nerve. 2000; 23(2):211-6. [PMID]
[7] Pomerance J, Fine I. Outcomes of carpal tunnel surgery with and without supervised postoperative therapy. Journal of Hand Surgery. 2007; 32(8):1159-63. [DOI:10.1016/j. jhsa.2007.05.001] [PMID]

[8] Janssen RG, Schwartz DA, Velleman PF. A randomized controlled study of contrast baths on patients with carpal tunnel syndrome. Journal of Hand Therapy. 2009; 22(3):2008. [DOI:10.1016/j.jht.2009.02.001] [PMID]

[9] Huisstede BM, Randsdorp MS, van den Brink J, Franke TPC, Koes BW, Hoogvliet P. The effectiveness of oral pain medication and corticosteroid injections for carpal tunnel syndrome: A systematic review. Archives of Physical Medicine and Rehabilitation. 2018; 99(8):1609-22.e10. [DOI:10.1016/j.apmr.2018.03.003] [PMID]

[10] Huisstede BM, Fridén J, Coert JH, Hoogvliet. Carpal tunnel syndrome: Hand surgeons, hand therapists, and physical medicine and rehabilitation physicians agree on a multidisciplinary treatment guideline-results from the European Handguide study. Archives of Physical Medicine and Rehabilitation. 2014; 95(12):2253-63. [DOI:10.1016/j. apmr.2014.06.022] [PMID]

[11] Walker WC, Metzler M, Cifu DX, Swartz Z. Neutral wrist splinting in carpal tunnel syndrome: A comparison of night-only versus full-time wear instructions. Archives of Physical Medicine and Rehabilitation. 2000; 81(4):424-9. [DOI:10.1053/mr.2000.3856] [PMID]

[12] Marshall SC, Tardif G, Ashworth N. Local corticosteroid injection for carpal tunnel syndrome. Cochrane Database of Systematic Reviews. 2007; (2):CD001554. [DOI:10.1002/14651858.CD001554.pub2] [PMID]

[13] Levine DW, Simmons BP, Koris MJ, Daltroy LH, Hohl GG, Fossel AH, et al. A self-administered questionnaire for the assessment of severity of symptoms and functional status in carpal tunnel syndrome. The Journal of Bone and Joint Surgery. 1993; 75(11):1585-92. [DOI:10.2106/00004623199311000-00002] [PMID]

[14] Rezazadeh A, Bakhtiary AH, Samaei A, , Moghimi J. [Validity and reliability of the Persian Boston questionnaire in Iranian patients with carpal tunnel syndrome (Persian)]. Koomesh. 2014; 15(2):138-45.

[15] Özyürekoğlu T, McCabe SJ, Goldsmith LJ, LaJoie AS. The minimal clinically important difference of the carpal tunnel syndrome symptom severity scale. The Journal of Hand Surgery. 2006; 31(5):733-8. [DOI:10.1016/j.jhsa.2006.01.012] [PMID]

[16] Jensen MP. The validity and reliability of pain measures in adults with cancer. The Journal of Pain. 2003; 4(1):2-21. [DOI:10.1016/j.jpain.2009.05.001] [PMID]

[17] Farrar JT, Young JP Jr, LaMoreaux L, Werth JL, Poole RM. Clinical importance of changes in chronic pain intensity measured on an 11-point numerical pain rating scale Pain. 2001; 94(2):149-58. [DOI:10.1016/S0304-3959(01)003499] [PMID]

[18] Kumar S, Fernando DJ, Veves A, Knowles EA, Young MJ, Boulton AJ. Semmes-Weinstein monofilaments: A simple, effective and inexpensive screening device for identifying diabetic patients at risk of foot ulceration. Diabetes Research and Clinical Practice. 1991; 13(1-2):63-7. [DOI:10.1016/01688227(91)90034-B] [PMID] 
[19] Fernandes CH, Meirelles LM, Raduan Neto J, Nakachima LR, dos Santos João BG, Faloppa F. Carpal tunnel syndrome with thenar atrophy: Evaluation of the pinch and grip strength in patients undergoing surgical treatment. Hand. 2013; 8(1):60-3. [DOI:10.1007/s11552-012-9471-8] [PMID] [PMCID]

[20] Steinberg DR, Szabo RM. Anatomy of the median nerve at the wrist. Open carpal tunnel release-classic. Hand Clinics. 1996; 12(2):259-69. [PMID]

[21] Huisstede BM, Hoogvliet P, Franke TP, Randsdorp MS, Koes BW. Carpal tunnel syndrome: Effectiveness of physical therapy and electrophysical modalities. An updated systematic review of randomized controlled trials. Archives of Physical Medicine and Rehabilitation. 2017; 99(8):1623-34. e23. [DOI:10.1016/j.apmr.2017.08.482] [PMID]

[22] Ritting AW, Leger R, O'Malley MP, Mogielnicki H, Tucker R, Rodner CM. Duration of postoperative dressing after mini-open carpal tunnel release: A prospective, randomized trial. Journal of Hand Surgery. 2012; 37(1):3-8. [DOI:10.1016/j.jhsa.2011.10.011] [PMID]

[23] Jerosch-Herold C, Shepstone L, Miller L. Sensory relearning after surgical treatment for carpal tunnel syndrome: A pilot clinical trial. Muscle \& Nerve. 2012; 46(6):879-84. [DOI:10.1002/mus.23421] [PMID] 
This Page Intentionally Left Blank 